\title{
APPLICATION OF STATIONARY GEODIMETER TO STUDY THE VELOCITY OF THE KOZEL'SKIY GLACIER MOVEMENT, KAMCHATKA, U.S.S.R.
}

\section{(Abstract)}

by

V.N. Vinogradov

(Institute of Volcanology, Petropavlovsk-Kamchatskiy, 683006, U.S.S.R.)

\begin{abstract}
Kozel'skiy glacier is located in lat. $53.1^{\circ} \mathrm{N}$., $50 \mathrm{~km}$ from the Pacific Ocean, and has a southern exposure. It flows from the saddle between Avachinskiy and Kozel'skiy volcanoes. Its highest point is at an altitude of $1850 \mathrm{~m}$ a.s.1. The glacier tongue descends to an altitude of $900 \mathrm{~m}$ a.s.l. At present, this is the best-studied glacier in Kamchatka.

In May and June 1981 , for the purpose of organizing routine monitoring of the movement of Kozel'skiy glacier, systematic geodimeter measurements were made at the "Mishennaya" Observatory. A model 8 geodimeter (AGA, Sweden) was used for measuring straight-line distances. The source of radiation was a $\mathrm{He}-\mathrm{Ne}$ laser beam with a power of $5 \mathrm{MW}$ and a wavelength of $0.6328 \mathrm{~m}$. In Kamchatka this geodimeter can measure distances of $60 \mathrm{~km}$ and in some cases $90 \mathrm{~km}$. If a special (diurnal) procedure of measurements is used, one can attain an accuracy of $1 \times$ $10^{-6}$ of the length of the line D. Sixteen prism-angle reflectors were installed on the glacier.

The entire firn area of the glacier could be seen well from the top of Mount Mishennaya. Two profiles consisting of six points on the glacier surface were constructed. A bench mark on the ancient lava flow of Kozel'skiy volcano was taken as static in elevation and was used to control the accuracy of the measurements. The points on the glacier were established by $2 \mathrm{~m}$ poles with a diameter of $1.5 \mathrm{~cm}$. Reflectors were installed on tripods and were centred with the help of an optical plumb bob. The points for measurement of the movement velocity were located at a
\end{abstract}

distance of more than $26 \mathrm{~km}$ from the instrument. Studies were carried out during periods of stationary images (without inversions), generally early in the morning and late in the evening.

Two-sided trigonometrical levelling was carried out simultaneously. Zenith distances were measured four times by a Teo-010A theodolite. Meteorological conditions were determined at $1.5-2 \mathrm{~h}$ near the reflectors and at the determined at 1.5 the whole cycle of measurements. The processing of the results of distance measurements was done according to the procedure published in Lobachev. The elevation of points over the observatory was determined from the measured zenith distances.

The error in distance measurements was $\pm 0.04 \mathrm{~m}$ and in elevation $\pm 0.8 \mathrm{~m}$ (an increase in accuracy up to $0.2 \mathrm{~m}$ is possible). The displacement of points of velocity changed from 0.3 to $2.37 \mathrm{~m}$ over the whole period of observation. This corresponds to a glacier velocity from 1 to $6 \mathrm{~m} / \mathrm{d}$. Thus, a cycle of geodimeter measurements may be carried out once a week, providing an accuracy of distance measurements of $\pm 4 \mathrm{~cm}$. Routine measurements of the velocities of glacier movement, using geodimeters, may be organized subject to reliable long-term attachment of reflectors to the surface of the glacier.

Experience of the studies made indicated good opportunities for application of a stationary geodimeter to the investigation of glacier movement. The data obtained agree with previous measurements made by the usual geodetic methods.

\section{INTER-RELATIONS BETWEEN THE ARCTIC SEA ICE AND THE GENERAL CIRCULATION OF THE ATMOSPHERE \\ (Abstract)}

\author{
by
}

\author{
G. Wendler, M. Jeffries and Y. Nagashima
}

(Geophysical Institute, University of Alaska-Fairbanks, Fairbanks, AK 99775-0800, U.S.A.)

\begin{abstract}
Satellite imagery has substantially improved the quality of sea-ice observation over the last decades. Therefore, for a 25 -year period, a statistical study based on the monthly Arctic sea-ice data and the monthly mean 700 mbar maps of the Northern Hemisphere was carried out to establish the relationships between sea-ice conditions and the general circulation of the atmosphere. It was found that sea-ice conditions have two opposing effects on the zonal
\end{abstract}

circulation intensity, depending on the season. Heavier than normal ice in winter causes stronger than normal zonal circulation in the subsequent months, whereas heavier than normal ice in the summer-fall causes weaker zonal circulation in the subsequent months. Analyzing the two sectors, the Atlantic and Pacific ones separately, a negative correlation was found, which means a heavy ice year in the Atlantic Ocean is normally associated with a light one in the Pacific Ocean and vice versa. 